\title{
How diets and the environment influence on the weight of Roman snail in captivity
}

\author{
Irina Tkachenko*, Sergey Tkachenko, and Viktor Dedkov \\ Immanuel Kant Baltic Federal University, 14 A. Nevskogo str., 236016 Kaliningrad, Russia
}

\begin{abstract}
This article presents the results of a study into the influence of the diet, air temperature and relative air humidity, and soil temperature on the average weight of Helix pomatia in captivity. It was shown that vegetables included in the mixed leaf-vegetable diet mitigated the effect of a high air temperature and a low relative humidity. It was established that the air temperature and relative humidity had opposite effects on weight gain in Helix pomatia. The increase in temperature predetermined the weight loss. Despite the high temperature, a humidity of over $75 \%$ caused all the molluscs gain weight regardless of their diet.
\end{abstract}

\section{Introduction}

The Roman snail (Helix pomatia) is widely collected for culinary purposes. The species owes its popularity to its gustatory qualities, large size, and high protein, amino acid, and microelement contents [4]. According to the European Red List of Non-marine Mollusks, France consumes 20-40 thousand tonnes of snail meat a year. The two most popular edible species are Cornu aspersum (Müller 1774) and Helix pomatia. Snail consumption is also considerable in the Mediterranean countries and Spain. Helix pomatia is a least-concern species and, in its European distribution, it is not threatened [5]. However, such considerable consumption of snail meat would be impossible without terrestrial mollusc farming.

In the South - Italy, Spain, Southern France - the guidelines and techniques for Helix pomatia farming are common knowledge [11]. The artificial breeding of the Roman snail in Southern Europe is simplified by that the molluscs do not go into winter hibernation. However, they have to 'rest' in hotter summer months. Other macro regions boasting favourable conditions for the Roman snail include Eastern Europe, the Baltics, and Russia (the Kaliningrad region). Unlike their southern counterparts, snails bred in these areas go into winter hibernation.

For a long time, Helix pomatia was habitually harvested on these territories to be sold in France and other countries of traditional snail consumption. As a result, the mollusc populations dwindled in southeastern and eastern region [9] and Russia (Kaliningrad

\footnotetext{
* Corresponding author: i.tkachenko-kld@yandex.ru
} 
region) [7]. In the Baltics, particularly, Lithuania, the number of Helix pomatia per square metre is falling to critical levels. At the same time, the harvest quotas are increasing.

All the above necessitates the artificial breeding of the Roman snail in Eastern Europe, the Baltics, and the Kaliningrad region. Southern techniques for snail farming will not be effective farther to the north. However, Roman snail farming may be economically feasible in Russia's Kaliningrad region or in Belarus [6].

It is necessary to identify the factors affecting the weight of the snail to increase the efficiency of Helix pomatia farming in the Kaliningrad region. Literature provides conflicting evidence about their impact. Some sources do not go into details and give general recommendations. They mention that the Roman snail needs warmth and high humidity, without specifying the temperature and humidity ranges [1]. The snail density rate is also affected by the characteristics of the soil. For instance, the characteristics of the snail are affected by the soil moisture. At the same time, the population size of Helix pomatia does not correlate with the calcium content in soils. Snail farming depend on favourable air temperature and relative air humidity ranges [10]. However, the cooling and heating of air temperature in a room is expensive. Thus, it is important to find a way to mitigate the negative influence of high summer temperatures - this problem is urgent in all the areas suitable for the Roman snail farming.

Another important factor affecting the weight of the snail is the diet. In Italy [11] and other south territories like Australia, temperature regulation is not considered at all, because snails are bred in the open sky. Researchers focus on nutrition and pest control. Italian farms use the burdock, the plantain, the sorrel, and the leaves of the beetroot as main feed and the sunflower and the leaves of the cabbage as a supplement [11]. On Australian farms, the clover, the spinach, the leaves of the turnip, etc. are fed to the snail. Supplements include the lettuce, the cabbage, and the carrot.

The above adds urgency to studies into the effect of different factors on the weight of the Roman snail. Moreover, it is important to establish a correlation between these factors. This work is focus on the investigate effect of the diet, the air and soil temperature, and the relative air humidity on the weight of the Roman snail with math methods.

\section{Materials and methods}

Perceivably healthy mature snails without any serious visible shell damage were selected for the experiment. In the Kaliningrad region, the Roman snail reaches maturity at the age of four years [7].

The Roman snails were collected at two sites (fig. 1). Site 1 was in the village of Rybachy in the Curonian Spit national park in the Kaliningrad region, 33 MAMSL, $55^{\circ} 09.37^{\prime} \mathrm{N}, 20^{\circ} 50.42^{\prime} \mathrm{E}, 02.07 .2017$, coll. I A Tkachenko (30 snails). Site 2 was at $\mathrm{km} 6$ of the Ladushkin-Kornevo highway in the Bagrationovsk district of the Kaliningrad region, 39 MAMSL, $54^{\circ} 31.50^{\prime} \mathrm{N}, 20^{\circ} 43.72^{\prime} \mathrm{E}, 02.07 .2017$, coll. I A Tkachenko (30 snails). The area of each collection site did not exceed $100 \mathrm{sqm}$. Molluscs from different sites were kept strictly apart. 


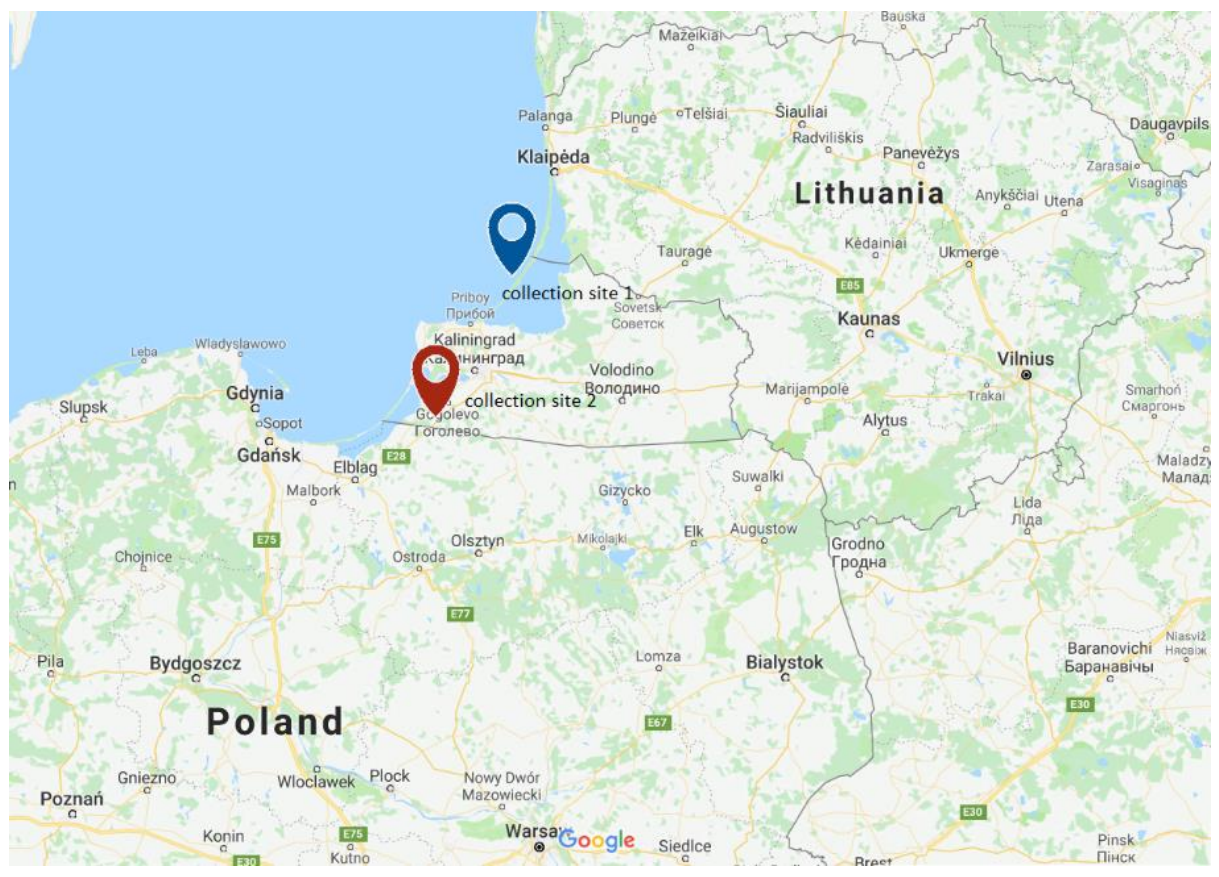

Fig. 1. Roman snail collection sites

Site 1 has a sandy soil with a high proportion of humus. The forest is mixed. The canopy consists of the Siberian hawthorn (Crataegus sanguinea Pall.), the rowan (Sórbus aucupária L.), and the common oak (Quércus róbur L.), with the dominance of the silver birch (Bétula péndula Roth). The understorey includes the blackberry (Rúbus plicátus Weihe \& Nees), the red raspberry (Rúbus idáeus L.), and the common nettle (Urtíca dióica L.). The herb layer is dominated by the common meadow-grass (Poa praténsis L.), the meadow fescue (Festuca pratensis Huds.), the bird's eye speedwell (Veronica chamaedrys L.), and the goosegrass (Gálium aparine L.). At this site, the raspberry, the blackberry, and the nettle are the preferred feed of the Roman snail.

Site 2 is a mixed forest in the floodplain of a stream, with the dominance of the Norway maple (Ácer platanoídes L.) and the common aspen (Pópulus trémula L.). The understorey is dominated by the Sosnowsky's hogweed (Heracléum sosnówskyi Manden.) and the butterbur (Petasites hýbridus L.) (the latter grows to $1 \mathrm{~m}$ and taller). The raspberry is also present in the layer. The herb layer includes the ground elder (Aegopódium podagrária L.), the lesser celandine (Ficária vérna Huds.), the tufted hairgrass (Deschampsia cespitosa L.), and the common nettle. The local snail's preferred feed is the butterbur. With a sod-podzol soil, this site offers an optimum environment for Helix pomatia.

Each group of 30 snails was divided randomly into three subgroups of ten. Two 'triads' representing two different collection sites were formed. Each group of ten snails was marked with a unique colour. We indicated the collection site (R for Rybachi (site 1) and L for Ladushkin (site 2)). An index number from 1 to 10 was randomly assigned to each snail.

Snails were placed into PE containers of a volume of 21 litres. Six and a half litres of soil were added to each container, forming an at least $8 \mathrm{~cm}$-thick layer, according to recommendations from Italy's farmers. The soil parameters were as follows: top sphagnum peat, chalk, PG-MIX compound fertiliser and microelements. The acidity reached $\mathrm{pH}(\mathrm{KCl})$ $=5.5-6.5$. To ensure air access, each container's lid was perforated with $5 \mathrm{~mm}$ holes 
throughout its area. During the experiment, the snails' metabolic wastes - excrements and mucus - and feed leftovers were removed from the container every day. A clean environment is crucial for the health of the Roman snail.

The temperature of room air, soil surface, and soil at a depth of $8 \mathrm{~cm}$ was measured using a mercury-in-glass thermometer calibrated to $0.2^{\circ} \mathrm{C}$. The relative air humidity was obtained using an Assman psychrometer. The thermometers were calibrated to $0.2{ }^{\circ} \mathrm{C}$. The weight of the snails was measured using an OHAUS Explorer EX-124 analytical balance, calibrated to $0.0001 \mathrm{~g}$.

The temperature and relative air humidity were measured before - and the temperature of the soil during - feeding. The snails were weighted once in three days if it was possible. The weight of each individual was registered. The preliminary weighting showed that the weight of each snail fluctuated significantly (up to \pm 2 grams) within 24 hours. Thus, we did the averaging of the weights of all snails in a group. The average weight was calculated for each group as the arithmetic mean. This approach made it possible to follow the general weight gain trend in each of the six groups. Random phenomena (a sudden weight loss or gain by some snails) were neutralised. Since the measurement error was very small, there was no need to calculate a confidence interval for the average weight.

The Spearman's rank correlation coefficient (Spearman's rho) was used for determining nature and closeness of the relationship between the average weight $\left(\mathrm{W}_{\mathrm{av}}\right)$ of each group of snails and environmental parameters: air temperature $\left(\mathrm{T}_{\text {air }}\right)$ and relative humidity $(\mathrm{RH})$ [3]. This nonparametric method was chosen because we obtain non-normally distributed dependent measures.

To identify the effect of a diet on the weight of snails, diets under consideration had to meet the following criteria:

1) be suitable for the Roman snail;

2) include different components (so that the preferable types of feed can be identified);

3) differ from each other;

4) exclude randomness (it is necessary to consider transitional diets comprising feeds used in other diets).

A daily ration is the amount of feed supplied to each group of snails daily to cover the molluscs' need for nutrients necessary to sustain life.

Based on these requirements we worked out the following rations.

Ration 1 'Herbs'.

The feed consisted of a mix of the plant leaves - a usual feed of the Roman snail in the Kaliningrad region. It included the red clover (Trifolium praténse L.), the white clover (Trifolium repens L.), the butterbur (Petasites hýbridus L.), the common nettle, and the greater burdock (Arctium láppa L.). We selected fresh leaves without any damage.

Ration 2 'Vegetables'.

It included a mixture of vegetables grown in the Kaliningrad region - the cucumber (Cucumis sativus L.), the tomato (Solánum lycopérsicum L.), the courgette (Cucurbita pepo subsp. pepo), the carrot (Daucus carota subsp. sativus Hoffm.), and the cabbage (Brássica olerácea L.).

\section{Diet 3 Mixed.}

The ration comprised a mixture of plant leaves and vegetables from the first two variants. This diet was expected to merge the benefits of rations 1 and 2 .

The molluscs were fed once a day. When feeding was impossible, a double ration was administered on the previous day. 


\section{Results}

On the collection day (02.07.2017), all the snails were marked and placed in containers. All the containers were kept at a well-ventilated laboratory of the Institute of Living Systems of the Immanuel Kant Baltic Federal University. The experiment was launched with a delay because a long spring had caused snails to come out on the surface later than expected. The observations began on July 3, 2017. Starting from that day, we measured the air and soil temperature and RH and recorded the current weight of the snails, which was later averaged for each group.

In the first two weeks each group was given $15 \mathrm{~g}$ of feed daily. In this period the diets were adjusted to meet the preferences of the Roman snail. The broadleaf plantain was to be replaced the first because the snails reluctantly ate it. For the same reason, the burdock was replaced with the butterbur. The nettle was not popular with snails, thus we reduced its content to 2 grams in the first and to 1 gram in the second ration. As to vegetables, we excluded the carrot (only couple of snails ate it) and the tomato (snails were eager to consume it but mould grew on the leftovers too fast, which could pose a risk to the snails' health). The tomato was replaced with the cucumber and the carrot with the courgette. Table 1 shows each group's indicators and diets adjusted to meet the preferences of the Roman snail.

Table 1. Groups of snails and their diets (adjusted)

\begin{tabular}{|c|c|c|c|}
\hline Group & Diet & Daily diet, g. & Diet composition \\
\hline R1 & Herbs & $10-12$ & Butterbur, nettle, clover \\
\hline R2 & Vegetables & 20 & Cucumber, courgette, cabbage \\
\hline R3 & Mixed & $10-12$ & $\begin{array}{c}\text { Butterbur, nettle, clover, cucumber, } \\
\text { courgette, cabbage }\end{array}$ \\
\hline L1 & Herbs & $10-12$ & Butterbur, nettle, clover \\
\hline L2 & Vegetables & 20 & Cucumber, courgette, cabbage \\
\hline L3 & Mixed & $10-12$ & $\begin{array}{c}\text { Butterbur, nettle, clover, cucumber, } \\
\text { courgette, cabbage }\end{array}$ \\
\hline
\end{tabular}

The total weight of feed given to each group was also altered. Groups R2 and L2 received $20 \mathrm{~g}$ and the others $10-12 \mathrm{~g}$ a day. In the first case, the ration was increased because there had been no leftovers from $15 \mathrm{~g}$ allotments. In the second case, the diet was reduced because the snails had left a significant amount of feed untouched. In this case the diet was reduced by 3-5 g for selected groups to prevent rotting and mould growth.

Three weeks after the start of the experiment (July 24, 2017), we decided to put group L1 on a vegetable diet because this group having shown the most dramatic weight loss among all the snails. Therefore, the diet was changed to prevent a decline in the snail population. After the change in the diet, the snails stopped losing weight.

In the first weeks, weight loss was observed in all the six groups, being the most dramatic in the snails from collection site 2. This could be a result of the total effect of unfavourable factors - the high air temperature and the deterioration of living conditions as compared with the optimum environment on the floodplain.

Until August 31,2017, the diets did not change. After that date, all groups were put on a vegetable diet, which proved to be the most effective for weight gain. On September 9, 2017 (day 69), all the snails were returned to their usual habitat. At the end of the experiment, some snails from R2 and L2 tried to lay eggs. One of the snails (from each 
group) succeeded (the others dug a distinctive hole and sat in it but they did not lay any eggs). Clutches was taken out of the soil and placed in a different container.

During most of the experiment, the air temperature was higher than, or close to critical value $\left(24^{\circ} \mathrm{C}\right)$. Also, relative humidity was below the minimum $(60 \%)$. Better environment conditions for weight gain were attained at the end of August.

Throughout the experiment, the soil surface temperature was $1.5-2^{\circ} \mathrm{C}$ below the air temperature. The temperature of the soil at a depth of $8 \mathrm{~cm}$ equalled the air temperature with an accuracy to the measurement error. For this reason, soil temperature was not considered a standalone parameter in the further analysis.

The observed difference in the air and soil surface temperatures probably relates to the vital functions of the snails. Excreting a considerable amount of mucus on the soil surface, the snails might have contributed to the regulation of the soil temperature. All this causes the surface temperature to drop. From experiment egg-laying requires a soil temperature of below $24{ }^{\circ} \mathrm{C}$ and a relative humidity of above $60 \%$.

\section{Discussion}

The experiment helped to establish that the weight of the Roman snail depended on both the external environment and the diet. Figures 2 and 3 show the dependencies of the average weight from time for groups R1, R2, R3 and L1, L2, L3 respectively. The air temperature is plotted along a secondary axis.

As figure 2 shows the diet has a significant effect on the weight of the snails. The group of snails put on a leaf diet was rapidly losing weight (R1 - the bottom plot). The group on a vegetable diet (R2 - the upper plot) was gaining weight and the group on a mixed diet (R3 - the plot in the middle) demonstrated median result. Weight loss is a result of unfavourable conditions - a high heat and a low humidity [2]. A familiar leaf diet did not mitigate the effect of the unfavourable factors and the snails had to activate the defence mechanism of summer hibernation. Vegetables included in the mixed diet mitigated the effect of a high temperature and a low humidity. Vegetable diet consists water-rich components helped the snails stay active and gain weight, thus cancelling out the effect of unfavourable conditions. Partly, this happened due to endogenous factors. Values of Spearman's rho $(\rho)$ between the average weight of snails from groups R1..R3 and environmental parameters are shown in Table 2. Similar values $\rho$ for groups L1..L3 are given in Table 3 .

As shown in Tables 2 and 3 all values of $\rho$ can separate into three categories according to their magnitude: $|\rho| \leq 0,1 ; 0,2 \leq|\rho| \leq 0,4$ and $|\rho| \geq 0,8$. A Spearman correlation of zero (in our case $|\rho| \leq 0,1)$ indicates that there is no tendency for average weight to any changes when one of air characteristics increases or decreases (no correlation between ranks).

Table 2. Values of Spearman's rho between the average weight of groups R1..R3 and environmental parameters in conditions of artificial breeding

\begin{tabular}{|c|c|c|c|c|}
\hline Parameter & Date interval & R1 & R2 & R3 \\
\hline \multirow{2}{*}{ Air temperature } & $06.07-30.08$ & $-0,33$ & 0,01 & $-0,20$ \\
\cline { 2 - 5 } & $30.08-08.09$ & $-0,91$ & 0,41 & $-0,99$ \\
\hline & & & & \\
\hline \multirow{2}{*}{ Relative humidity } & $06.07-30.08$ & 0,40 & 0,05 & 0,38 \\
\cline { 2 - 5 } & $30.08-08.09$ & 0,80 & $-0,32$ & 0,85 \\
\hline
\end{tabular}

If the value of the correlation coefficient is in the range of $0,2 \leq|\rho| \leq 0,4$, we can talk about a weak closeness of the relation between two variables. The Spearman's correlation 
coefficient is positive (positive correlation) if average weight tends to increase when value of air temperature or relative humidity increases. The Spearman's correlation coefficient is negative (negative correlation) in case the opposite relationship.

Table 3. Values of Spearman's rho between the average weight of groups L1..L3 and environmental parameters in conditions of artificial breeding

\begin{tabular}{|c|c|c|c|c|}
\hline Parameter & Date interval & L1 & L2 & L3 \\
\hline \multirow{3}{*}{ Air temperature } & $03.07-15.07$ & $-0,94$ & $-0,92$ & $-1,00$ \\
\cline { 2 - 5 } & $18.07-30.08$ & 0,07 & $-0,10$ & $-0,22$ \\
\cline { 2 - 5 } & $30.08-08.09$ & $-1,00$ & $-0,82$ & $-0,96$ \\
\hline \multirow{3}{*}{ Relative humidity } & & & & \\
\cline { 2 - 5 } & $03.07-15.07$ & 0,29 & 0,33 & 0,08 \\
\cline { 2 - 5 } & $18.07-30.08$ & $-0,30$ & $-0,18$ & 0,39 \\
\cline { 2 - 5 } & $30.08-08.09$ & 0,91 & 0,99 & 0,93 \\
\hline
\end{tabular}

The third category of Spearman's rho $|\rho| \geq 0,8$ mean a strong positive or negative between two variables. For these values of $\rho$ test of the significance was passed (variables have statistical dependence).

For groups of snails collected on the Curonian spit, two date intervals were identified:

1. 06.07-30.08 - period with high air temperatures and low relative humidity;

2. 30.08-08.09 - at this time, there was a decrease in air temperature below $24^{\circ} \mathrm{C}$ and an increase in relative humidity of more than $60 \%$.

The first three days of the experiment (03.07-06.07) could be another period, but it duration is too short, so these dates don't take into account for analyze behavior of groups R1..R3. Weight gain in the first days of the experiment was explained by the improvement of living conditions as compared to the natural environment.

The classic behavior of a Roman snail is weight gain, when there are no adverse conditions, otherwise the snail defends itself against unfavorable environmental influence falling into hibernation. Due to this defense mechanism snails minimize the impact of high heat and low RH but they lose weight.

As shown in Table 2 under adverse conditions (high air temperature and low RH) snails tend to protect themselves. So, the correlation coefficient between average weight and air temperature for the group R1 (vegetable diet) is -0.33 . This value indicates a weak negative correlation. It means that the snails reduce the impact of high air temperature by creating epiphragm and hibernation.

For the group R3 we can see decreasing magnitude of Spearman's rho between the average weight and air temperature in comparison with $\mathrm{R} 1$. It means that dependence between these two parameters is weakened. Such a result is highly likely associated with the diet.

No correlation between average weight and air temperature is observed for group R2 $(\rho=0.01)$. In this case can be argued that snails from R2 completely block the influence of high heat.

The same period (06.07-30.08) is characterized by a weak positive correlation between $\mathrm{W}_{\mathrm{av}}$ and relative humidity. Consequently, humidity and air temperature effect on average weight oppositely. For snails from the Curonian spit humidity has a greater impact than air temperature. Because magnitude of Spearman's rho between $\mathrm{W}_{\mathrm{av}}$ and RH more than similar value $\rho$ between $\mathrm{W}_{\mathrm{av}}$ and air temperature for groups R1 and R3. Probably this is caused to the peculiarities of the biotope. In ecosystems of the Curonian spit Roman snails live on dry sandy soils, so they are more resistant to high temperatures and at the same time use all the protective functions when the humidity increases. 


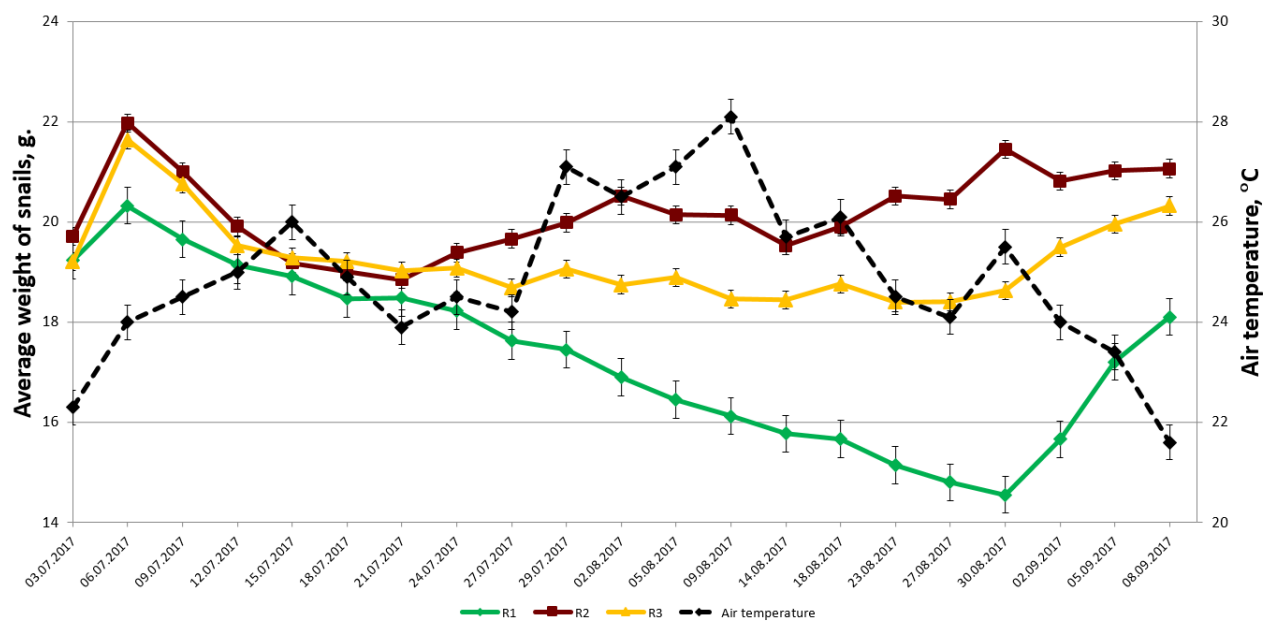

Fig. 2. The dependences of the average weight of snails from groups R1, R2, and R3 and the air temperature.

Also, as for the air temperature, we can see the independence of the snail's weight from the $\mathrm{RH}$ for the $\mathrm{R} 2$ group despite the adverse environmental conditions. Consequently, we can be argued that a vegetable diet allows to neutralize influence of high air temperature (above $24{ }^{\circ} \mathrm{C}$ ) and low relative humidity (less than $60 \%$ ).

After 30.08 the ambient temperature began to decrease and relative humidity increased. For this period, we observe perfect Spearman correlation between $\mathrm{W}_{\mathrm{av}}$ and air temperature (negative) also between $\mathrm{W}_{\mathrm{av}}$ and $\mathrm{RH}$ (positive). It means that in this period of time the environmental parameters and diet are the most favorable snail's existence (weight gains all time). But for the group R2, at the same period, there is 'abnormal' Spearman correlation: positive between $W_{a v}$ and air temperature, negative between $W_{a v}$ and $R H$. Observed values of Spearman's rho for R2 can caused that some snails from this group laid eggs, so they have become weight less. Therefore, the $\mathrm{W}_{\mathrm{av}}$ of group $\mathrm{R} 2$ have decreased.

Despite the high temperature, when the humidity was above $75 \%$, the Roman snails were gaining weight across all the three groups (the peaks were observed on August 18, 2017 , see the plot). Thus, the optimum diet for the snails from site 1 consists of vegetables. To prove that this result is not random, we included Roman snails from a different biotope (site 2) into the experiment. The snails from site 2 showed similar results, which suggests that the patterns observed are universal.

According to data shown in figure 3, all other factors being equal, the diet has a significant effect on the weight of snails. Three date intervals were allotted for groups of Roman snails collected in the Ladushkin area. We should be add another one period of time because all Roman snails from groups L1..L3 had initial stress and long-term adaptation. The appearance of the adaptation period is explained by the fact that these snails were taken from the ecological optimum. Stress is the nonspecific response of the body to any demand (removal from the natural habitat, captivity, overcrowding, or a new diet). This response involves avoidance of food and, as a result, weight loss. 


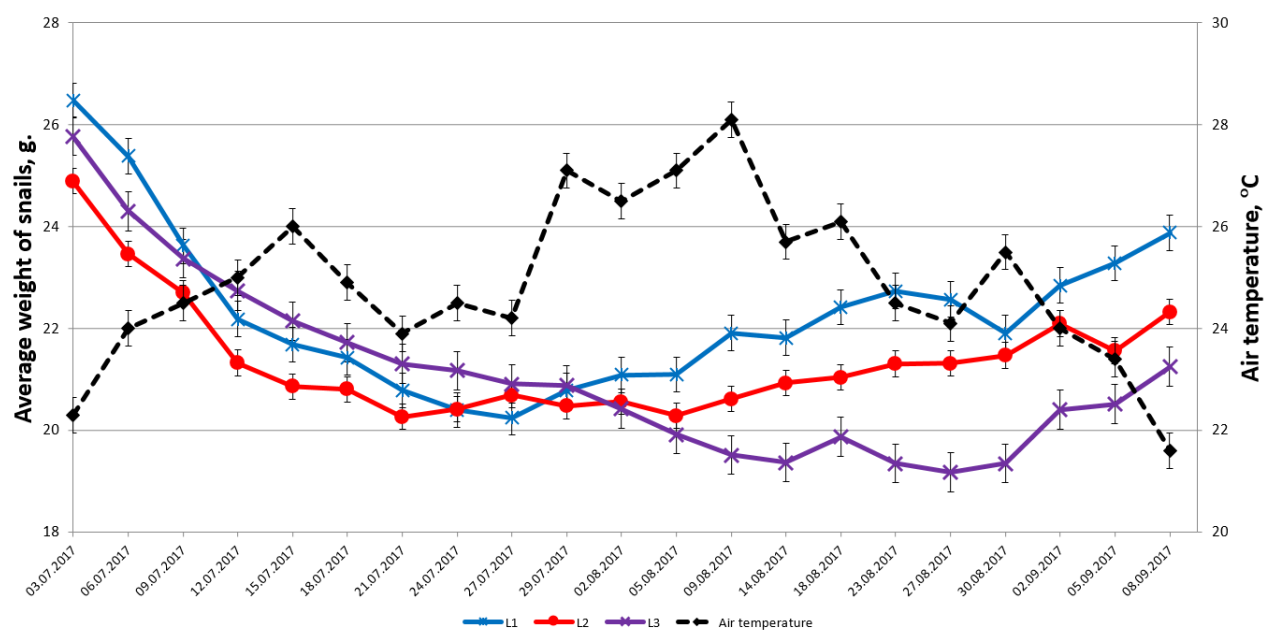

Fig. 3. The dependences of the average weight of snails from groups L1, L2, and L3 and the air temperature

The stress period has continued about two weeks: from 03.07 till 18.07. At this time, groups L1..L3 lost weight regardless of the diet. The main reason of losing weight is high heat. This conclusion is based on perfect negative Spearman correlation between average weight and air temperature for each group L1..L3 (see table 3). From other side we obtain weak positive correlation between average weight and relative humidity. This non-classical behavior can serve as a stress marker for Roman snails. As mentioned above, group L1 was put on a vegetable instead of a leaf diet. As a result, an increase in the average weight of the group was observed from July 29, 2017. Group L3 was receiving a mixed feed (leaves and vegetables) and performed worse than L1 and L2.

Values of Spearman's rho between average weight and air temperature for the second date interval (18.07-30.08) for group L1..L3 are very close to the same values for group $\mathrm{R} 1 \ldots \mathrm{R} 3$ in period 06.07-30.08. Magnitudes of $\rho$ for groups L1 and L2 (vegetable diet: L2 from start, L1 since 24.07) are very close to zero. This fact serves as proof that the vegetable diet levels the effects of high heat, regardless of the prehistory of snails. Also, we got almost the same values of the correlation coefficient between average weight and air temperature: $-0.20(\mathrm{R} 3)$ and -0.22 (L3) for snail's groups fed with the Mix diet. It might say about a common effect of the Mix diet on snails from different biotopes.

However, of Spearman's rho between average weight and humidity for similar date interval (18.07-30.08) are not close to zero and are even negative for the groups L1 and L2. Such results can be associated with biotopic features, also the influence of endogenous factors - the snails themselves moistened the soil with their mucus, getting enough moisture from the vegetables, so they didn't depend on air humidity. It also speaks in favor of the vegetable diet front of the others.

Weak positive correlation between average weight of snails and relative humidity are observed for group L3 for second date interval. We get equal values $\rho$ for group snails taken from different biotopes: 0.38 (P3) and 0.39 (L3), which once again confirms the monotony of the influence of the Mix diet.

After the group had been put on a vegetable diet on August 30, 2017, the snails started to gain weight rapidly, which proves the effectiveness of such a diet. We can see perfect positive Spearman correlation between average weight and relative humidity and perfect 
negative Spearman correlation between average weight and air temperature. All groups of L1...L3 behave like a typical Roman snail.

A slight decrease of the correlation coefficient between weight and temperature for L2 compared to other groups is also associated with egg laying (like for R2). In group L1, which had not received vegetable feed at the beginning of the experiment, there were no cases of mating or egg-laying.

\section{Conclusion}

Therefore, the best diet for the snails from an optimum environment was that consisting of vegetables. The benefits of such a diet include a high content of moisture and microelements. All this helps the Roman snail to withstand the unfavourable environmental factors and even to continue reproduction (a second clutch during the year).

The temperature and the relative humidity have opposite effects on the weight of the Roman snail. An increase in the temperature causes the snails to activate defence mechanisms - excreting mucus or digging themselves into the soil to lower the temperature and going into hibernation. Part of the molluscs put on a leaf diet avoided food and hid in the shell, sealing the aperture with a calcareous epiphragm. All this made it possible for the snails to minimise their losses.

A snail's diet affects the choice of a defence mechanism and partially mitigates the effect of high temperatures. The relative humidity also affects the activity, motility, and nutrition of the Roman snail. A higher humidity is associated with greater activity and mucus excretion. In this case, the soil in the container may become over-moisturised, which can cause mould growth. This aspect should be taken into account in snail farming. The type of the collection site also affected the weight of the snail. Snails from ecological optimum have long-term stress period adaptation to the artificial breeding conditions. Group R1 was able to restore after two months of losing weight. This behaviour is an evidence of the quality of the Roman snail's defence mechanisms.

\section{References}

1. J. Błoszyk, J. Kacprowicz, Z. Książkiewicz-Parulska, Folia Malacologia, 24(2), 103106 (2016)

2. M.Y. Çelik, M.B. Duman, M. Sariipek, Uzun G. Gören, Kaya D. Öztürk, S. Karayücel, Journal of Agricultural Sciences, 25, 189-196 (2019)

3. G.W. Corder, D.I. Foreman, Nonparametric Statistics, A Step-by-Step Approach (Wiley, 2014)

4. V.B. Meyer-Rochow, Encyclopedia of Food Security and Sustainability, 1, 376-378 (2019)

5. E. Neubert, M.B. Seddon, D.J. Allen, J. Arrébola, T. Backeljau, I. Balashov, R. Bank, R. Cameron, A.M. de Frias Martins, W. De Mattia, I. Dedov, M. Duda, G. Falkner, M. Falkner, Z. Fehér, O. Gargominy, D. Georgiev, F. Giusti, B.J. Gómez Moliner, K. Groh, M. Ibáñez, H. Kappes, G. Manganelli, A. MartínezOrtí, G. Nardi, M.T. Neiber, Páll- B. Gergely, A. Parmakelis, V. Prié, A. Reischütz, P.L. Reischütz, B. Rowson, J. Rüetschi, R. Slapnik, M. Son, V. Štamol, D. Teixeira, K. Triantis, K. Vardinoyannis, T. von Proschwitz, F. Walther, European Red List of Terrestrial Molluscs (IUCN: Cambridge, UK and Brussels, Belgium, 2019)

6. S.N. Panteley, The Problems of the Belarusian Fishing Industry, 25, 136-139 (2009) 
7. E.G. Rumyantseva, V.P. Dedkov, Ruthenica, Russian Malacological Journal, 15(2), 131-138 (2005)

8. O. Schmut, P. Roll, M. Reich, W. Palm, Z Naturforsch C., 35(5-6), 376-385 (1980)

9. E.A. Snegin, O.Y. Artemchuk, Russian Journal of Genetics, 53(3), 348-357 (2017)

10. V. Sterbova, J. Kupka, J. Thomas, J. Lichnovsky, P. Andras, Land snail assemblages of production forest in relation to selected environmental factors (Hrabeticky Forest, Czech Republic), 15th International Multidisciplinary Scientific GeoConference SGEM 2015, 5(2), 295-300 (2015)

11. L. Zagata, L-A. Sutherland, Journal of Rural Studies, 38, 39-51 (2015) 